\title{
Research on the Influencing Factors of Urban Traffic Carbon Emissions and the Development of Low Carbon Transportation
}

\author{
Bo Gao \\ ${ }^{1}$ Liaoning Police College, Dalian, Liaoning, 116036
}

Keywords: Influencing Factors, Urban Traffic Carbon Emissions, Development, Low Carbon Transportation

\begin{abstract}
Urban low-carbon transportation is a practical problem and it is also an academic hotspot. At present, the field has accumulated a wealth of research results, discussed the methods of traffic reduction, low-carbon transportation to achieve the path, foreign experience, the specific city of low-carbon traffic construction strategies and low-carbon transportation systems and other issues. Problems that need further study include: Comprehensive analysis of the benefits of various elements of transportation, improvement of urban low-carbon transportation systems, tracking of low-carbon transportation construction practices, and analysis of foreign experiences.
\end{abstract}

\section{Introduction}

Urban low-carbon transportation construction is a major theme of China's transportation construction, and it is also a hot issue in academic circles in recent years. Scholars of many disciplines have conducted extensive and in-depth discussions on this issue with their respective perspectives and methods, and have put forward a wealth of theoretical perspectives and countermeasures. Systematically sorting out and summarizing these documents, clarifying the orientation of existing research, we can find problems that need further study, and help us to explore the growth points of innovation, which is of great significance for promoting low-carbon urban construction [1].

\section{Analysis of Influencing Factors of Urban Transportation Carbon Emissions}

The issue of urban transportation carbon emissions is a complex and comprehensive issue. To reduce carbon emissions, we must first find out what factors affect the growth of carbon emissions.

The rational use of land resources determines the layout of regional functional areas, and relates to the residents' distance to travel, the choice of travel modes, and the total amount of travel, which further influences the amount of carbon emissions from transport. If land resources are developed with a single function and people live in places where they are living, working, and relaxing, they will increase their reliance on the long-term mobility, extend the travel distance of motor vehicles, increase energy consumption, and further expand carbon emissions. With the development of complex functions of resources, people's travel distance will be shortened, which will reduce the dependence on motor vehicles and increase the walking or riding trip rate, thereby reducing carbon emissions [2].

There are many forms of transportation nowadays, such as rails, buses, subways, bicycles, cars and motorcycles. When the same amount of traffic is completed, the energy consumption of different means of transport is positively correlated with the amount of exhaust emissions. That is, fewer vehicles with low energy consumption emit less exhaust gas. According to statistics, within the unit traffic, the carbon emissions of walking and cycling are zero, the carbon emissions of rail transit are 0.7 , the carbon emissions of buses are 1.0, and the carbon emissions of motorcycles are 27. 5. The car's carbon emissions are 19.0. More carbon emissions are still motorcycles and cars.

One of the key factors directly affecting the carbon emissions of transport is the energy conservation and emission reduction technology of vehicles. The pollutants emitted by vehicle exhaust mainly include hydrocarbons, nitrogen oxides, carbon monoxide, particulates, etc. They are 
mainly discharged through discharge pipes. Compared with other provinces, transportation vehicles are relatively backward in energy-saving and emission-reduction technologies. Vehicles consume a lot of energy and have low utilization rates, resulting in a large amount of carbon emissions. The technical level of energy-saving and emission-reducing vehicles can be expressed in several aspects: the problem of vehicle weight, engine displacement and fuel consumption, brake energy recovery, and auxiliary equipment energy consumption.

The transportation infrastructure mainly includes road network layout and parking spaces that are driven by transportation vehicles. If the function of the road system is confusing, it will hinder the convenient and rapid transportation, and then extend the travel time of guests. Therefore, it is necessary to functionally partition the road. According to the traffic function, roads are mainly divided into four categories: fast roads, trunk roads, sub-dry roads, and branch roads. Different road grades require different vehicle speeds. Only reasonable combination and combination can satisfy different levels of transportation needs and make urban traffic more efficient and reduce carbon emissions.

The transport policy refers to the government's policy of directly or indirectly participating in the operation and development of transportation. The transportation policy can guide people's travel modes, mobilize the fuel tax of automobiles, road congestion fees for traffic, and investment costs for transportation development, and adjust and allocate road space resources and road space supply conditions. At the same time, the government uses information management means (intelligent transportation), such as the establishment of an intelligent public transport system, to improve the traffic efficiency, actual loading rate, and service quality of public transport, so as to effectively reduce the carbon emissions of urbanized public transport.

\section{Definition of Low Carbon Transportation in Chinese Cities}

After more than 30 years of reform and opening up, China's people's living standards have been significantly improved, but regional differences are relatively large and there is still a large gap between the levels of moderately developed countries. China's road density is less than $40 \%$ of the developed countries, and the per capita road length is also less than $50 \%$ of that in developed countries. China's 1,000-person car ownership is less than $10 \%$ of the lowest level in developed countries. In general, the level of humanistic development of most cities in China except some cities is relatively low, and achieving sustainable economic and social development is still the top priority for China in the next 50 years [3]. According to the actual conditions of China's economic and social development and with reference to the concept of sustainable development of transport, we believe that low-carbon transportation in Chinese cities can be defined as: Urban low-carbon transportation is based on maximizing the demand for socio-economic development on urban transportation. The connotation of urban low-carbon transportation can be understood from the following four aspects:

Urban low-carbon transportation is not a new mode of transportation but a new development concept. Its core lies in improving the energy efficiency of transportation, improving the energy use structure of transportation, optimizing the development mode of transportation, and guiding people to travel reasonably. Its purpose is to increase the carrying capacity while reducing energy consumption and carbon emissions, providing safe, convenient, comfortable and fair services for people and logistics, and continuously satisfying people's production and living needs for urban transportation.

Urban low-carbon transportation construction is a systematic project. Planning, construction, maintenance, transportation, production, use of vehicles, related systems, technical support measures, people's travel modes, transportation and consumption patterns, etc. all need to be transformed and optimized with the concept of "low carbonization" to realize transportation.

Urban low-carbon transportation construction is an effective way to achieve sustainable urban development, and it must adapt to the local level of humanistic development. With the acceleration of urbanization in China and the improvement of people's quality of life, residents are increasingly pursuing motorized modes of travel. In the process of accelerating the construction of urban 
transportation, it is necessary to shift the use of high-carbon and high-carbon emissions mainly from land and fossil energy. Extensive development methods, especially at this stage need to increase energy-saving emission reduction efforts to achieve sustainable development of urban transport.

Encourage the use of low-energy-consumption vehicles and methods in the construction of urban transport infrastructure and transportation options, minimize the use of energy and minimize greenhouse gas emissions, and achieve the flow of as many people and goods as possible. Social economy, urban transportation, and resources and environment are coordinated and developed.

\section{The Construction of Urban Low-Carbon Traffic}

Urban low-carbon transportation construction is a complex project involving many aspects. Scholars either conduct research on the whole and propose systemic countermeasures; or conduct special research on certain aspects and propose corresponding measures.

Scholars who conduct research as a whole seek to put forward comprehensive countermeasures. Some scholars have suggested that the countermeasures to promote the development of low-carbon transportation in China include six aspects: First, promote low-carbon transportation to the national strategic level and integrate it into urban development planning; second, adjust the urban traffic structure and build urban rail transit as the backbone. Urban transport system; Third, pay attention to the convergence and integration of various transport modes; Fourth, establish a complete bicycle and pedestrian travel system; Fifth, develop clean energy, and build a low-carbon transport energy supply system; Sixth, strengthen the international low-carbon transportation technology. Some scholars have also found that urban low-carbon transportation construction faces lagging development of public transportation, a drastic reduction in the degree of non-motorized travel of residents, lack of effective demand management, and weak awareness of energy conservation and emission reduction. Urban traffic management systems are incompatible with urban low-carbon transportation construction. In view of this, the strategic direction of urban low-carbon transportation construction is to popularize the concept of urban low-carbon transportation, use technology to plan and manage cities and their transportation, and shape the structure of low-carbon cities; the main approach is to guide the development of cities and improve traffic demand management [4].

Other scholars believe that building a convenient mode of transportation based on public rail transit, vigorously developing a slow-moving transportation system, limiting the growth of private cars in cities, encouraging new energy technologies, rational land use, and traffic planning modes are examples to adapt to China's national conditions. Some scholars also pointed out that to achieve low-carbon urban passenger transportation goals must be taken simultaneously and multi-pronged. First, it is necessary to build citizens' low-carbon transportation ethics in order to improve the cultural awareness of low-carbon travel; Second, low-carbon engineering measures should be taken to achieve carbon reduction in urban passenger transport by means of science and technology; Third, investment and financing channels should be broadened to solve urban passenger transport. The capital bottleneck of transportation low carbonization; Fourth, we must establish a scientific urban public transport planning, so that the implementation of public transport priorities. Taken together, these studies emphasize that the government must attach great importance to and plan low-carbon transportation in cities. Cities should adopt various measures to develop low-carbon transportation at the same time, including adjusting the urban structure, developing public transportation and slow traffic, and limiting cars. Cultivate residents' awareness of low-carbon travel, and innovate energy production and utilization technologies.

Studying from a certain perspective or aspect can often make the research more fully. Some scholars advocate vigorously developing urban rail transit to promote the integration of rail transit and conventional traffic, thereby improving the operational efficiency of urban transport, reducing the use of cars, and achieving the goal of reducing carbon emissions from urban transport systems and advancing low-carbon urbanization. Some scholars also believe that the development of large cities in China to speed up the development of rail transit, and build urban transport system with urban rail transit as the backbone, can greatly reduce the intensity of urban emissions. Other 
scholars have studied the impact of the bus system in China on low carbon, and believe that the bus system has a great impact on low carbon. To build a low carbon society, we must reform the bus system. The first is to change the concept of traditional bus consumption and enhance the concept of low-carbon society. Second, government procurement takes the path of green procurement. Third, monetization subsidies are not linked to the administrative level. The public and experts participate in the development of car-repair standards. Fourth, information feedback is established. Mechanisms to increase the effectiveness of public supervision; Fifth, use decentralized management and information technology to restrict bus violations. There are also scholars specializing in the development strategy of urban low-carbon transportation and propose that low-carbon transportation is a utility choice. Only when low-carbon things are more comfortable, more convenient, and more cost-effective than things that are not low-carbon, people will consciously choose Low-carbon transportation, so improving the utility of low-carbon urban transportation is the basic measure for developing low-carbon transportation. Some scholars have studied the issue of low-carbon transportation protection from a legal point of view. They believe that the development of low-carbon transportation industry in China needs the support and cooperation of policies and laws in related fields: On the one hand, timely introduction of the elements of low-carbon transportation in the revision of laws, soundness and Improve the policy and legal system; On the other hand, we must adjust and upgrade the legal orientation of energy-saving and emission-reduction policies, and gradually form a special legislation for the low-carbon transportation industry. Some scholars also analyzed the root causes of non-low-carbon travel by residents, and proposed that policies, education, and publicity should be used to vigorously cultivate residents' low-carbon travel modes, including formulating travel restrictions that severely discriminate against low-carbon requirements, and widely disseminating knowledge on various travel modes. Guide residents to establish low-carbon travel concepts as soon as possible and provide accurate travel information services. The above research has carried out detailed discussions on topics such as the development of rail transit, reform of the bus system, expansion of low-carbon traffic utility, establishment of low-carbon transport law protection, and cultivation of residents' low-carbon travel modes, making the city's low-carbon transportation more solid.

By improving the level of public transport services, more residents are encouraged to choose public transport as their main mode of travel. The transportation department should select appropriate transportation methods according to the different travel distances, construct a perfect urban rail transportation system to undertake long-distance transportation, actively develop buses to undertake middle-distance transportation, encourage the development of bicycles, and connect buses and subway stations within a short distance. Refute, realize the seamless connection of different modes of transportation and shorten the travel time of residents. Adopt public transport priority strategies and provide citizens with more public transport options by subsidizing residents using public transportation to provide subsidies such as free public transport cards. Due to historical reasons, at present, the urban road network is irregular and the route is serpentine or detour. At the same time, there are also a large number of overlaps in different lines, which causes the waste of road resources and transport capacity and causes traffic jams. Therefore, it is possible to carry out bus lines through public transport companies. Improve management, improve the quality of service, and shorten passengers' transit time [5].

The government manages traffic through mandatory laws and regulations and administrative orders. Restrict the number of car parks and parking spaces in the central area, increase the parking fees, carry out automobile license auctions, increase fuel tax, and when conditions are ripe, collect traffic congestion fees, and pay for city expenses when crossing downtown. Through these methods, the cost of using private cars in urban areas is increased, so that more residents can switch from choosing private cars to choosing public transport. In the urban area, more and more perfect bus lanes will be built. At the same time, the traffic department will strengthen supervision and increase penalties for the use of public transport lanes. It will truly speed up public transport compared to other modes of transportation and reduce travel time for passengers. 


\section{Conclusion}

China's urban low-carbon transportation construction should take the concept of urban low-carbon transportation as the basic guiding ideology and popularize it for the whole people. In addition, with the aid of scientific and technological progress, scientific planning and scientific management of cities and their transportation should be carried out to construct a low-carbon urban comprehensive transportation system. To shape the shape and structure of low-carbon cities is also the strategic direction of current low-carbon transportation construction in Chinese cities. The main approaches for the construction of low-carbon transportation in Chinese cities are: public transport to guide urban development, demand management, improves the traffic management system, technology innovation and promotion.

\section{Acknowledgements}

Fund Project: Dalian Social Science Association (Social Sciences) Project 201-2018 Annual Project Number 2017dlskyb152

\section{References}

[1] Zhang Taoxin, Zhou Yueyun, Zhao Xianchao. The current situation and approach of low-carbon transportation construction in Chinese cities [J]. Urban Development Research, 2011( 1) : 68 -80.

[2] Breaking into. Jinan city low carbon transportation construction [D]. Jinan: Shandong University, 2011.

[3] Su Taoyong, Zhang Jianhui, Li Jinliang, et al. An Empirical Study on the Influencing Factors of Urban Transportation Carbon Emissions: Evidence from Panel Data of Beijing, Tianjin and Shanghai Stocks [J]. Industrial Engineering and Management, 2011(10) : 134 - 138.

[4] Sun Ni. Research on Optimization of Transportation Mode Based on Carbon Emission [D]. Qinhuangdao: Yanshan University, 2014.

[5] Qiu Xiaoyan, Liu Haichun. Yangzhou city traffic carbon emission estimation [J]. Journal of Yangzhou Vocational University, 2015(12): 48 - 51. 